University of Nebraska - Lincoln DigitalCommons@University of Nebraska - Lincoln

USGS Staff -- Published Research

US Geological Survey

2017

\title{
Effects of Industrial and Investigator Disturbance on Arctic-Nesting Geese
}

Brandt W. Meixell

Alaska Science Center, bmeixell@usgs.gov

Paul L. Flint

Alaska Science Center

Follow this and additional works at: https:// digitalcommons.unl.edu/usgsstaffpub

Part of the Geology Commons, Oceanography and Atmospheric Sciences and Meteorology Commons, Other Earth Sciences Commons, and the Other Environmental Sciences Commons

Meixell, Brandt W. and Flint, Paul L., "Effects of Industrial and Investigator Disturbance on Arctic-Nesting Geese" (2017). USGS Staff -- Published Research. 1020.

https://digitalcommons.unl.edu/usgsstaffpub/1020

This Article is brought to you for free and open access by the US Geological Survey at DigitalCommons@University of Nebraska - Lincoln. It has been accepted for inclusion in USGS Staff -- Published Research by an authorized administrator of DigitalCommons@University of Nebraska - Lincoln. 
Research Article

\title{
Effects of Industrial and Investigator Disturbance on Arctic-Nesting Geese
}

\author{
BRANDT W. MEIXELL, ${ }^{1}$ U.S. Geological Survey, Alaska Science Center, 4210 University Drive, Anchorage, AK 99508, USA \\ PAUL L. FLINT, U.S. Geological Survey, Alaska Science Center, 4210 University Drive, Anchorage, AK 99508, USA
}

\begin{abstract}
Oil and gas development on the Arctic Coastal Plain (ACP) of Alaska, USA may have effects on Arctic-nesting birds. To estimate effects of industrial activity and investigator disturbance on avian productivity, we monitored nests of greater white-fronted geese (Anser albifrons) with digital cameras and periodic nest visits during 2013-2014 at 2 sites on the ACP. A disturbed site was adjacent to human-made infrastructure and industrial clean-up activities initiated at the onset of the study and a control site was $>2 \mathrm{~km}$ from sources of industrial disturbance. We assessed variation in estimates of incubation constancy, nest survival, and predator behavior relative to site, year, and distance from industrial activity using nest photographs obtained at 1-minute intervals. We compared analysis of hourly nest survival informed by intensive monitoring with cameras to analysis of daily nest survival informed by traditional nest visit data obtained at intervals of $5-7$ days to assess how method and time scale of sampling affect ecological inference. Geese in both sites exhibited high levels of nest attendance and initiated incubation breaks less than once per day. Observer-caused incubation breaks associated with nest visits $(\bar{x}=37.8 \mathrm{~min})$ were longer than other types of incubation breaks $(\bar{x}=8.7 \mathrm{~min})$, demonstrating a differential response by nesting geese to direct human encroachment versus indirect vehicular and aircraft traffic. During both years, geese were absent from nests more frequently in the disturbed $(\bar{x}=0.9$ breaks/day) than $\operatorname{control}(\bar{x}=0.6$ breaks/day) site, and this break frequency was slightly higher for nests closer to industrial activity. In the year with high rates of depredation, nest survival was positively related to distance from industrial activity and abandoned infrastructure, consistent with predictions of industry-caused effects. This relationship, however, was not evident in the year with reduced predation pressure, likely because of annual variation in arctic fox (Vulpes lagopus) behavior. Analysis of nest survival probability informed by camera data allowed for detection of detailed patterns of variation that were not supported when using only visit data for the same nests. Observer visits were responsible for reductions of $7-35 \%$ in nest survival probability, highlighting the importance of minimizing, and controlling for, observer effects in studies of avian productivity. Indirect vehicular and aircraft disturbance posed less risk to nest survival than direct encroachment by observers at nest sites. Therefore, effects of industrial activities on avian productivity in the Arctic can be minimized through practices that limit direct encounters with nests. Published 2017. This article is a U.S. Government work and is in the public domain in the USA.
\end{abstract}

KEY WORDS Anser albifrons, Arctic Coastal Plain of Alaska, camera monitoring, disturbance, greater white-fronted goose, incubation constancy, nest survival, observer effect, oil and gas development, predators.

The National Petroleum Reserve in Alaska (NPR-A) encompasses $>9.5$ million ha of federally managed land on the Arctic Coastal Plain (ACP) of northern Alaska, USA where it supports a diversity of wildlife, including millions of migratory birds. The Bureau of Land Management (BLM) is responsible for regulating the use, occupancy, and development of federal land in the NPR-A to protect wildlife and mitigate effects of oil and gas leasing (BLM 2015). Within the NPR-A, construction of the first oil production facility was initiated in 2015, and active leasing and exploratory operations

Received: 23 December 2016; Accepted: 9 June 2017

${ }^{1}$ E-mail: bmeixell@usgs.gov demonstrate potential for future oil and gas development (BLM 2015). The ACP is largely undeveloped and sparsely inhabited, raising concerns about the effects of human activities on the area's abundant wildlife. Potential effects of industrial activity could be indirect (e.g., destruction of habitat, increased predator abundance through construction of infrastructure) or direct (e.g., disturbance, displacement of birds caused by human activities; Hockin et al. 1992, National Research Council [NRC] 2003, Liebezeit et al. 2009), but little is known about the potential magnitude of such effects in currently undeveloped regions of the Arctic. In addition, wildlife studies designed to assess effects of industrial activity may influence avian behavior and reproductive success via investigator-caused disturbance (Carney and Sydeman 1999, Bentzen et al. 2008, Uher-Koch et al. 2015). As such, detailed knowledge of bird 
response to human activities associated with industrial operations, including factors related to research activity, is necessary to inform management practices that minimize effects on breeding birds in the Arctic.

During the late 1950s, the United States Air Force established a Distance Early Warning Line radar station at Point Lonely, Alaska (Point Lonely Short Range Radar Site; radar station) where buildings, radar antennas, and fuel tanks were constructed along with a network of gravel roads and a $1.6-\mathrm{km}$ runway capable of supporting large aircraft. In the 1970s, an oil exploration drill pad was established $1.5 \mathrm{~km}$ to the west of the radar station. These 2 sites are $>100 \mathrm{~km}$ from any other existing development. The radar station and the drill pad have been abandoned, resulting in minimal human presence, although infrastructure in terms of roads, buildings, and radar antennas remained. A cleanup effort to remove solid waste and contaminated soil from the drill pad was initiated during summer 2013, and demolition of buildings and other infrastructure at the radar station commenced in summer 2014. This cleanup operation provided an opportunity to assess how nesting birds in the Arctic that were not habituated to human activity might respond behaviorally to the presence of regular industrial disturbance.

Greater white-fronted geese (Anser albifrons; whitefronted geese) are the most abundant goose species in Arctic Alaska, where they nest in open upland tundra and meadow habitats (Stehn et al. 2013). Nesting geese tend to have high incubation constancy (i.e., $95 \%$ of time spent on nests), which facilitates egg development and protects eggs from predation (Prop et al. 1984, Thompson and Raveling 1987, Afton and Paulus 1992). Whereas nesting geese in the Arctic are capable of defending their nests from many potential predators, the vulnerability of eggs to predation increases substantially when incubating adults are absent from the nest (Samelius and Alisauskas 2001, Bêty et al. 2002). Therefore, human activity poses a risk to productivity if it causes incubating females to flush from their nests, or remain absent from nests for extended periods. The effects of vehicular, aircraft, and investigator disturbance on nesting waterfowl in the Arctic, the distance to which disturbance effects reach beyond the point source, and the degree to which birds may habituate to repeated stimuli are generally unknown and little studied but have important implications for future industrial development at locations across the ACP.

Avian incubation constancy and reproductive success have historically been estimated by time-intensive visual monitoring (Weller and Derksen 1972) and investigator visits to nest sites on periodic intervals (Mayfield 1961). Visit-based procedures have limited ability to accurately determine timing and identify cause-specific sources of nest failure (Sargeant et al. 1998, Larivière 1999, Williams et al. 2002), and may at times result in misclassified nest fate (Klett et al. 1986). Further, visiting nests may influence behavior of nesting birds or predators (Bêty and Gauthier 2001, Bolduc and Guillemette 2003). Nest monitoring with remote cameras has gained popularity as an approach to overcome such limitations, having been employed most frequently for predator identification (Pietz and Granfors 2000, Anthony et al. 2004, Liebezeit and Zack 2008) and to quantify incubation constancy (Hoover et al. 2004, Jónsson et al. 2007) but also for modeling nest survival probability and estimating effects of investigator disturbance (McKinnon and Bêty 2009, Stien and Ims 2015). Camera monitoring improves resolution in discerning nest fate (i.e., on the scale of min rather than days), which allows for analysis of nest survival at finer temporal scales and may lead to gains in statistical inference. Most studies suggest that camera effects are minimal (Coates et al. 2008, McKinnon and Bêty 2009, Stien and Ims 2015), although in some cases, cameras may influence behavior of nesting birds and predators (Anthony et al. 2006, Richardson et al. 2009).

We monitored white-fronted goose nests over 2 breeding seasons using digital time-lapse cameras and periodic nest visits to quantify patterns of nest attendance and survival in the vicinity of an industrial clean-up operation in Arctic Alaska. We monitored a sample of nests at 2 distinct sites: the disturbed site adjacent to industrial activities, and the control site where effects of industrial disturbance were presumed to be minimal. Our primary objectives were to compare estimates of attendance, survival, and sources of egg depredation between nests in the disturbed and control sites to assess effects of industry-caused disturbance on goose productivity; quantify the effects of investigator-caused disturbance and the presence of cameras on nest survival and incubation constancy; and relate predator composition and activity to observed variation in nest attendance and survival. Finally, we sought to examine the hypothesis that analysis of hourly nest survival informed by camera monitoring would yield improvements in accuracy and precision over daily nest survival informed only by visit data.

\section{STUDY AREA}

We conducted our study adjacent to the Point Lonely radar station (N70.910, W153.245) and abandoned drill pad (N70.909, W153.294) within the Teshekpuk Lake Special Area of the NPR-A (Fig. 1), which is managed by the BLM (BLM 2015). The arctic climate is characterized by a short growing season (Jun-Aug), high annual variation in daily temperature (range $=-30^{\circ} \mathrm{C}-8^{\circ} \mathrm{C}$ ), and low average annual precipitation ( $140 \mathrm{~mm}$; Gallant et al. 1995). Goose nesting habitat consisted of low elevation ( $<10 \mathrm{~m}$ above sea level) sedge tundra adjoining halophytic meadows associated with the Smith River drainage (Tape et al. 2013). Short vegetation height $(<15 \mathrm{~cm})$ provided minimal visual nesting cover and nests were often associated with microtopographic features consisting of high- and low-centered polygons, tussocks, and hummocks. The primary nest predators on our study area were arctic foxes (Vulpes lagopus), parasitic jaegers (Stercorarius parasiticus), and glaucous gulls (Larus byperboreus); less common predators included common ravens (Corvus corax), snowy owls (Bubo scandiacus), and brown bears (Ursus arctos).

We identified 2 sites within our study area based on proximity to industrial activities: the disturbed site encompassed habitats in the immediate vicinity (i.e., $<600 \mathrm{~m}$ ) of cleanup activities where nests were exposed to industry-related noise and visual 


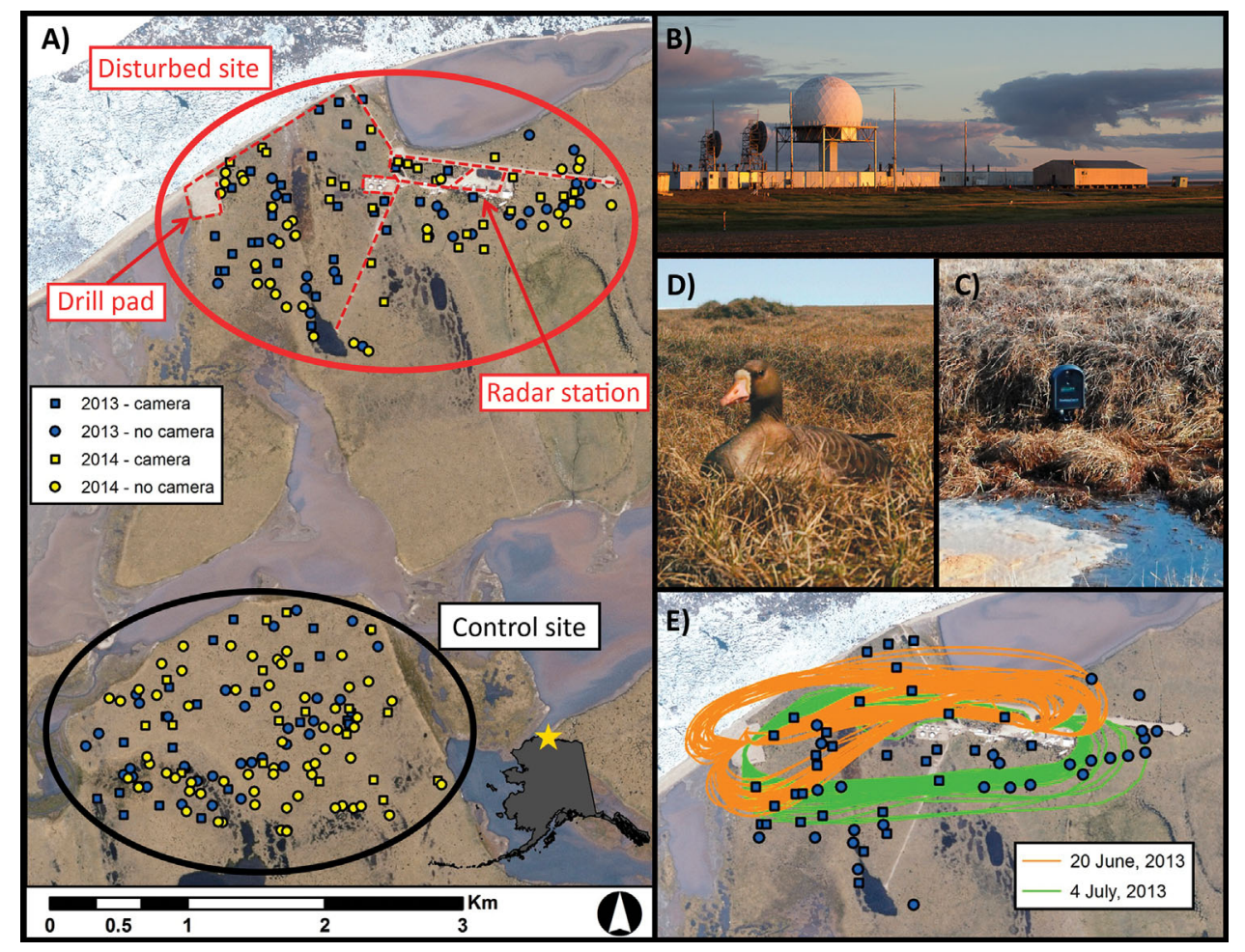

Figure 1. Study area, study sites, and locations of white-fronted goose nests adjacent to the Point Lonely Short Range Radar Site within the National Petroleum Reserve in Alaska, on the Arctic Coastal Plain of Alaska, USA. (A) The area susceptible to industrial disturbance (disturbed site) is outlined by the solid red line; the solid black line depicts the control site. Dashed red lines represent vehicular travel routes. Squares represent nests monitored with digital timelapse cameras and circles represent nests monitored without cameras in 2013 (blue) and 2014 (yellow). (B) Infrastructure associated with the radar station and industrial activity. (C) Digital camera used to monitor goose nests, placed at ground level adjacent to microtopography. (D) Incubating white-fronted goose. (E) Global positioning system tracks of helicopter traffic within the disturbed site on 20 June (orange) and 4 July (green) 2013.

stimuli and the control site, located approximately $3 \mathrm{~km}$ south of the radar station and presumably beyond the influence of anthropogenic disturbance (Fig. 1A). The 2 sites were separated by the Smith River and the area within each site was approximately $4 \mathrm{~km}^{2}$; the minimum distance between nests in control and disturbed sites was $>2 \mathrm{~km}$, with a midpoint to midpoint distance between sites of approximately $4 \mathrm{~km}$ (Fig. 1A). Industrial activities that represented potential sources of disturbance to nesting birds included nearly constant operation of heavy machinery, regular vehicular travel and human presence on gravel pads and established roads, periodic landings and takeoffs by fixed-wing aircraft on the runway, and occasional low-level transport of cargo by helicopter. Aside from industrial activities, habitat characteristics at both sites were similar, differing predominantly by the presence of human-made infrastructure (e.g., buildings, radar antennas, gravel roads, runway) at the disturbed site (Fig. 1B). In 2013, industrial activities commenced during peak nest initiation, whereas in 2014, industrial activities were underway several weeks prior to nest initiation.

\section{METHODS}

\section{Nest Monitoring}

During 2013 and 2014, we began searching for whitefronted goose nests on foot during the second week of June, corresponding with the onset of egg laying. We recorded locations of nests on handheld global positioning system (GPS) units and candled all eggs within a clutch to determine stage of incubation (Weller 1956). We individually labeled eggs with a sequence number representing lay order (Flint and Sedinger 1992) to aid in identification of partial-clutch depredation. For a subset of nests located within the disturbed and control sites, we placed digital timelapse cameras (Wingscapes, Moultrie, Lafayette, LA, USA) at ground level, approximately 5-10 m from the nest bowl, at the time of discovery. We positioned cameras within depressions in the ground or adjacent to microtopography so that they did not extend higher than the local terrain (Fig. 1C) to provide concealment and minimize the attraction of predators. Date and time were synchronized on all cameras and they were programmed to capture photographs on 1-minute intervals, with an expected battery life of 7 days. We revisited nests every 5-7 days to record fate (i.e., active, failed, successful), clutch size, and incubation stage, and to replace camera batteries; we covered eggs with nesting material upon completion of each nest visit. Within each site, we re-visited all nests on the same day and researched the site for additional nests; nest visits occurred primarily between 1400 and 2100 hours. We moved cameras from nests that failed to active nests nearby. We determined the ultimate fate of nests via visits independent of the camera data to allow for comparison of techniques. We considered nests successful if we observed $\geq 1$ gosling or detached shell 
membrane. All procedures were approved by Alaska Science Center's Animal Care and Use Committee, United States Geological Survey (2013-09), and were authorized by United States Fish and Wildlife Service (MB789758) and Bureau of Land Management (BLM AK FF09571).

\section{Photograph Evaluation}

For each nest photograph, we categorized the female as incubating, present, or absent. We considered a female to be incubating when she was directly covering the eggs (Fig. 1D), present when she was visible in the photograph and within the vicinity $(\sim 10 \mathrm{~m})$ of the nest (i.e., not incubating but available to defend against predators), and absent when she was not visible in the photograph (i.e., possibly unavailable to defend against predators). We also recorded the presence of investigators, documented predator observations and the behavioral response of geese to predators, and noted whether or not a predator was successful in depredating $\geq 1$ egg. When we could not determine the success of a predator from photographs, we used clutch size information recorded during nest visits to attribute depredation events to observed predators. We categorized photographs in which the status of a female could not be determined (e.g., because of fog or camera misalignment) as uninterpretable and censored them from analyses. We considered nests successful when goslings were first visible in a photograph, and failed when the source of nest failure (i.e., predator, observer) was first present in a photograph. We attributed the source of failure to the observer for instances in which a nest was depredated before the female returned following an observer visit. We also attributed to the observer instances of nest abandonment in which a female did not return to incubate following a visit.

\section{Incubation Constancy Analyses}

Disturbance likely poses a risk to productivity when it causes the female to depart the nest, reducing her ability to defend against predators. We predicted that effects of disturbance, if present, would result from reductions to incubation constancy (i.e., the amount of time females spent on nests). To quantify patterns of incubation constancy, we assessed sources of variation in length and frequency of incubation breaks. We defined an incubation break as the duration of time during which a female was absent from the nest. Specifically, an incubation break was considered to start at the time of the first photograph in which the female was absent, and the break ended when the female returned and resumed incubation. We categorized the cause of each incubation break as observer or non-observer. We defined observercaused breaks as absences resulting from a nest visit, whereas non-observer breaks consisted of all other sources of absence including those initiated by the female and those resulting from industrial activities or predators. In addition to estimates of break length and break frequency, we report overall estimates of incubation constancy representing the proportion of all interpretable photographs for which a female was not on an incubation break.
We conducted incubation constancy analyses using SAS 9.4 (SAS Institute, Cary, NC, USA).

Length of incubation breaks.-We used analysis of covariance (ANCOVA) on log-transformed data to assess factors that influenced the length (min) of incubation breaks. We used site (control and disturbed), year, and cause (observer and non-observer) as categorical factors, and day of incubation and hourly temperature as continuous covariates. We included the 2-way interactions between site, year, and cause to account for annual variation in characteristics of industrial activity, and an interaction between hourly temperature and cause because observer-caused breaks occurred disproportionately during warmer periods of the day. We obtained air temperature records from a long-term monitoring station (Lake 145) located $30 \mathrm{~km}$ from our study site (Urban and Clow 2016). Using only nests in the disturbed site, we considered a model in which length of break varied relative to distance from industrial activity after controlling for year, day of incubation, cause, temperature, and the 3-way interaction between year, cause, and temperature. We calculated distance from industrial activity as the straight-line distance $(\mathrm{m})$ between a given nest and the nearest travel corridor (i.e., road, gravel pad, runway) or structure (Fig. 1A). We calculated predicted values of break length at mean values of temperature and day of incubation.

Frequency of incubation breaks.-We used count-based regression to assess patterns of variation in break frequency. Because breaks were a relatively rare event (i.e., typically $<1$ break/day), the likelihood of detecting a break was related to the sample size of nest photographs on a given day. Therefore, we included only days for which we obtained $>1,000$ interpretable photographs for a given nest. We used site and year as categorical factors and day of incubation as a continuous covariate. We included a dummy variable coded as 1 for days in which we visited a nest (i.e., initiated an observer-caused break). Using a full model, we considered 4 distributions including Poisson, zero-inflated Poisson, negative binomial, and zero-inflated negative binomial. We assessed model fit by examining the predicted proportion of zero observations and Akaike's Information Criterion (AIC). All distributions closely predicted the correct proportion of zero observations, so we based model selection only on AIC. Given the best-fitting distribution (i.e., zeroinflated Poisson, Akaike weight $\left[w_{i}\right]=0.98$ ), we retained this structure for all subsequent modeling and reporting of results. We considered 2 variants of this base model: the first expanded the visit effect to include the day of the observer visit and the day after the visit, whereas the second estimated effects separately for the day of, and the day after, a nest visit. We designed these observer effect parameters to account for the possibility that nesting geese may compensate for observer-caused breaks by reducing subsequent breaks. To assess the potential influence of temperature on break frequency, we used a daily measurement of temperature recorded at 1,500 hours as an index of peak daily temperature; this was the time of day when the highest frequency of breaks occurred and we assumed that there was a general correlation in temperature within days. 
To produce predicted values of break frequency, we estimated the $L^{\prime} \beta$ s and associated standard errors for the Poisson and zero inflation parameters while holding site, year, age, and temperature at fixed values within the range of data. We then used the PopTools add-in program (version 3.2.5, www.poptools.org) for Microsoft Excel (Microsoft, Redmond, WA, USA) to run Monte Carlo simulations resampling the $L^{\prime} \beta$ s based upon their standard errors and generated 1,000 estimates of break frequency for each combination of fixed values. We report the mean and 95\% confidence intervals of these Monte Carlo estimates. To assess variation in the timing of incubation breaks, we summed the number of observer-caused and non-observer breaks within each site and year by hour of day. Because of the potential for unequal sampling intensity across all factors, we reduced these counts to the relative proportion of breaks (observer-caused and non-observer) occurring within year and hour for each site.

Helicopter effect.-On 2 days during 2013, a Robinson R44 helicopter (Robinson Helicopter Company, Torrance, CA, USA) operated continuously for approximately 7 hours at an altitude of $40-50 \mathrm{~m}$ between the radar station and the drill pad. The helicopter flight path traveled directly over or adjacent to the majority of nests in the disturbed site (Fig. 1E). Aircraft overflights are a source of disturbance to wildlife, although the general consensus is that helicopters cause more disturbance than other types of aircraft (Gladwin et al. 1987, BLM 2015). Because helicopter activity is frequently associated with resource exploration and development in the Arctic, understanding the effects of this activity on nesting geese is important for informing management practices (BLM 2015). To directly assess variation in incubation constancy attributed to helicopter activity, we compared the frequency and duration of incubation breaks for nests within the disturbed site on the helicopter days to the same nests in the disturbed site on the day immediately following the helicopter days.

\section{Nest Survival Analyses}

We conducted 3 separate analyses to assess sources of variation in nest survival probability. The first analysis included nests that were monitored with cameras and we determined ultimate fate from photographs. The primary objectives of this analysis were to assess differences in survival between nests in the control and disturbed sites, and to quantify the effect of investigator visits on nest survival. Whereas traditional nest survival analyses rely on information obtained through periodic nest visits over a number of days, the fates of nests monitored with cameras in our study were discernible on the scale of minutes. Therefore, we constructed encounter histories in the first analysis to allow for the estimation of hourly survival probabilities (HSP) of nests with cameras (camera-HSP). We assessed variation in precision and accuracy of survival estimates between cameramonitored and visit-monitored nests by reanalyzing data from nests monitored with cameras to estimate daily survival probabilities (DSP) using only information from visits to discern nest fate (camera-DSP). Hence, the camera-DSP analysis contained the same nests as the first analysis, allowing for a direct comparison of results between methodologies.

Finally, to identify potential effects of cameras on nest survival, we assessed variation in DSP of nests with and without cameras (camera-effect-DSP). The spatial distribution of nests monitored without cameras in the disturbed site was skewed farther from sources of disturbance (median $=263 \mathrm{~m}$ ) than those monitored with cameras (median $=162$ $\mathrm{m})$, especially in the number of nests monitored within $100 \mathrm{~m}$ of disturbance (camera $=22$, no camera $=9$ ). Therefore, we restricted this analysis to only nests located within the control site. To maintain consistency in methods, we used only information from nest visits to assign nest fate.

We conducted all nest survival analyses using the nest survival module in Program MARK (Dinsmore et al. 2002, Rotella et al. 2004) and assessed model support using AIC corrected for sample size $\left(\mathrm{AIC}_{c}\right)$. To minimize redundancy, we omitted models from further consideration if their $\mathrm{AIC}_{c}$ values were greater than a nested model with fewer parameters, or a model with an additional parameter but otherwise identical structure (Burnham and Anderson 2002, Arnold 2010). We back-transformed estimates of HSP (first analysis) and DSP (second and third analyses) from the logit link and calculated nest success $(\hat{S})$ as the cumulative product of all DSP assuming a 24-day incubation period, or all HSP at 576 hours (Ely and Dzubin 1994). Our estimates of nest success represent the probability that $\geq 1 \mathrm{egg}$ in a given nest hatched. We calculated variances associated with backtransformed estimates using the delta method (Seber 1982).

Hourly nest survival.-For the camera-HSP analysis, we constructed encounter histories for each nest as the hour found ( $i$ ), the last hour known to be alive $(j)$, the hour failed or hatched $(k)$, and the ultimate fate (successful or failed) of the nest $(l)$. The earliest that a camera was deployed was the nineteenth hour of 9 June, and we standardized this as hour 1. We collected images until the thirteenth hour of 12 July ( $h r$ 787). We censored encounter histories to the last hour of known fate when the camera failed prior to hatch or failure. To account for likely sources of variation in nest survival and to limit the number of models considered, we conducted model selection in a 2 -stage approach. In stage 1 , we assessed temporal and spatial variation in nest survival by considering a candidate set of 9 models in which HSP was either constant or varied by year, by year and site, or by year, site, and day of incubation. We then used the top approximating model from stage 1 as base structure in stage 2 of model selection where we assessed support for variation in HSP relative to investigator nest visits and distance from industrial disturbance (distance). The distance variable applied only to nests within the disturbed site.

To assess the effects of observer visits on HSP, we coded nests as 0 (not visited) or 1 (visited) for every hour of the study (Rotella et al. 2004). Because the duration of incubation breaks following nest visits often spanned hourly intervals, we coded as 1 the hourly interval in which a nest was visited and the 2 subsequent intervals. Thus, nest failures 
occurring $<3$ hour following a nest visit were attributed to the observer effect. When an observer visit was known to cause failure (i.e., the nest was depredated following an observer visit and prior to the return of the female), we coded the nest as alive in the interval of the visit and as failed in the interval immediately following the visit. In stage 2 of model selection, we considered a suite of models in which HSP varied relative to either observer, distance, observer and distance, or to interactions of observer and distance, or year and site.

To quantify the magnitude of the observer effect, we first calculated nest success using the top-supported model containing the observer effect but without the observer effect coefficient; this yielded estimates of nest success in the absence of observer visits. We then calculated nest success from a model that did not contain an observer effect but was otherwise identical; this yielded estimates of success that included the effect of observer visits. The difference between these 2 estimates yielded the reduction to nest success attributed to observer nest visits, given our visitation schedule (Bentzen et al. 2008, Wilson et al. 2012).

Daily nest survival. - We constructed encounter histories for the camera-DSP and camera-effect-DSP analyses, which both used nest visit data to discern fate, as the day found (i), the last day known to be alive $(j)$, the last day visited or potentially visited prior to hatch $(k)$, and the ultimate fate of the nest (l). The first day that we found a nest was 9 June, and we standardized this as day 1 . The last day we monitored a nest was 13 July (day 35). We monitored a subset of nests $(n=6)$ with cameras for only part of incubation; encounter histories for these nests were split based on the presence of a camera and treated as different nests in the dataset. Because we lacked substantial variation in nest visit intervals (i.e., all nests within a given site were visited on the same days), we were unable to consider an observer effect in the DSP analyses (Rotella et al. 2000). For the camera-DSP analysis, the candidate model set was identical to the camera-HSP analysis but excluded models containing the observer effect. The candidate model set for the camera-effect-DSP analysis was analogous to the camera-DSP analysis but did not consider models assessing variation by site in stage 1 , and instead of the distance variable in stage 2 , we considered variation relative to the presence of cameras.

\section{Predator Observation Summary}

We summarized predator observations relative to site, year, and time of day to gain further insight into patterns of incubation constancy and nest survival. We considered each suite of photographs depicting a predator visit to a nest as a single occasion for which we categorized the predator to species and type (avian vs. mammalian), the hour in which the occasion was initiated, whether or not the predator was successful, and if the depredation event was partial or complete.

\section{RESULTS}

Over 2 years, we monitored 247 white-fronted goose nests; of these, 113 were located in the disturbed site and 134 were located in the control site. We used digital time-lapse cameras set to record on 1-minute intervals and obtained 1.64 million interpretable photos of 54 nests in 2013 (control $=22$; disturbed $=32$ ) and 44 nests in 2014 (control $=18$; disturbed $=26$ ); $4.1 \%$ of photographs were uninterpretable and censored from analyses. The number of interpretable photographs varied by site and year $\left(2013_{\text {control }}\right.$ $=262,876 ; 2013_{\text {disturbed }}=553,273 ; 2014_{\text {control }}=334,829$; $\left.2014_{\text {disturbed }}=489,393\right)$.

\section{Incubation Constancy}

White-fronted geese showed high levels of incubation constancy. Using only non-observer incubation breaks, incubation constancy was $99.2 \%$. Including observer-caused incubation breaks, incubation constancy was $97.7 \%$. Given that some portion of observer-caused breaks compensated for non-observer breaks, true incubation constancy for undisturbed birds is likely bracketed by these 2 estimates.

Length of incubation breaks. - The distribution of break lengths was highly skewed with a maximum of 1,900 minutes. The log transformation successfully normalized these data. Break length varied most strongly by cause of break $\left(F_{1}, 677=677, P<0.001\right)$; observer-caused breaks averaged 37.8 minutes $(95 \% \mathrm{CI}=34.3-41.6)$, whereas nonobserver breaks averaged 8.7 minutes $(95 \% \mathrm{CI}=8.2-9.1)$. The effects of year and site were considerably smaller and not consistent. Generally, breaks were longer in 2013 than in 2014, and longer within the control site than the disturbed site (Fig. 2). Length of incubation breaks was not related to hourly temperature or day of incubation. When we partitioned the data to only the disturbed site, we found an effect of distance that differed depending on the cause of the nest break $\left(F_{1,826}=12.06, P<0.001\right)$, but effect sizes were small. For observer-caused breaks, the distance effect on break length was positive, with an estimated increase of 3-5 minutes for a nest at $400 \mathrm{~m}$ compared to one at $50 \mathrm{~m}$ (Table S1, available online in Supporting Information). The length of non-observer breaks tended to be shorter for nests farther from industrial activity, with a predicted difference of 3 minutes for nests at $50 \mathrm{~m}$ and $400 \mathrm{~m}$ (Table S1).

Frequency of incubation breaks. - After censoring nest-days for which we obtained $<1,000$ interpretable photos $(n=347)$, our dataset for estimating incubation break frequency included 1,148 nest-days. Non-observer breaks were infrequent, generally occurring less than once a day. The frequency of non-observer breaks was higher for nests in the disturbed site and increased with day of incubation and peak daily temperature, but there was no effect of year (Figs. 3 and 4). On average, nesting females in the disturbed site took 0.3 more non-observer breaks/day than those in the control site $\left(\bar{x}_{\text {disturbed }}=0.9\right.$ breaks/day, $\bar{x}_{\text {control }}=0.6$ breaks $/$ day; Fig. 4). At some times of day, observer-caused breaks were almost as common as non-observer breaks (Fig. 3). The effect of observer nest visits on break frequency was best described by reducing the probability of a non-observer break on the day a nest was visited $\left(w_{i}=0.74\right)$. We found less support for models that extended the observer effect to subsequent days $(\Delta \mathrm{AIC}>3)$. When we partitioned the data 


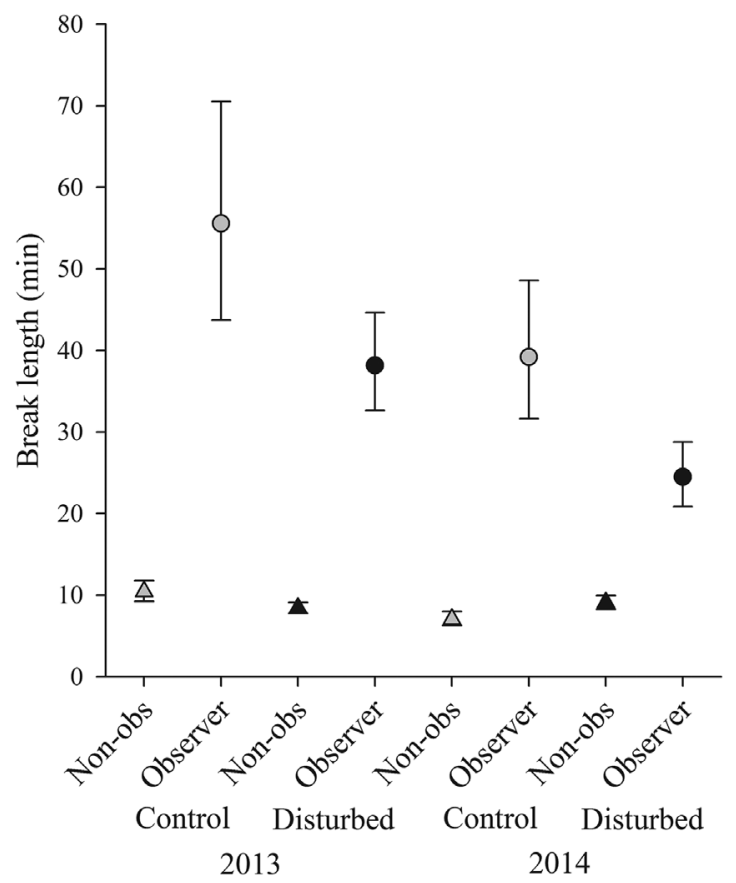

Figure 2. Duration of incubation breaks ( $\min \pm 95 \% \mathrm{CI}$ ) for nesting white-fronted geese occurring in disturbed (black) and control (gray) sites on the Arctic Coastal Plain of Alaska, USA, 2013-2014. Circles depict incubation breaks caused by observer nest visits and triangles depict breaks that were independent of nest visits (non-obs).

to only the disturbed site, we found a negative effect of distance from disturbance on frequency of non-observer breaks $(t=-2.43, P=0.015)$. The magnitude of this effect for a nest at $50 \mathrm{~m}$ as compared to one at $400 \mathrm{~m}$ was 0.9 breaks/day in 2013, but only 0.2 breaks/day in 2014 (Table S2).

Helicopter effect.-We identified 29 pairs of nest-days (i.e., helicopter use days and the day immediately following) from 23 nests that had sufficient samples of images to compare nesting behavior. There was no effect of localized helicopter activity on frequency of nest breaks or time off of nests. The average number of incubation breaks on the high-intensity helicopter use days (1.3 breaks/day, $95 \% \mathrm{CI}=0-3.7)$ was similar to the day immediately following (1.1 breaks/day, $95 \% \mathrm{CI}=0-3.5)$. Likewise, total time off the nest did not differ on the helicopter use days $(8.7 \mathrm{~min} /$ day, $95 \%$ $\mathrm{CI}=6.4-11.1)$ compared to the next day $(9.7 \mathrm{~min} /$ day, $95 \% \mathrm{CI}=7.4-12.1)$.

\section{Nest Survival}

Hourly survival of camera nests. - We analyzed encounter histories of 98 white-fronted goose nests monitored with cameras in the disturbed $(n=58)$ and control $(n=40)$ sites for 37,294 exposure hours. Of all nests, 26 hatched, 23 failed, and 49 were censored to the hour of known fate as a result of battery failure late in incubation $(n=43)$ or camera removal from active nests $(n=6)$. On average, battery failure for censored nests occurred $2.2 \pm 2.0$ (SD) days before their estimated hatch dates. Of the 43 nests for which cameras were present but did not document ultimate nest fate, field
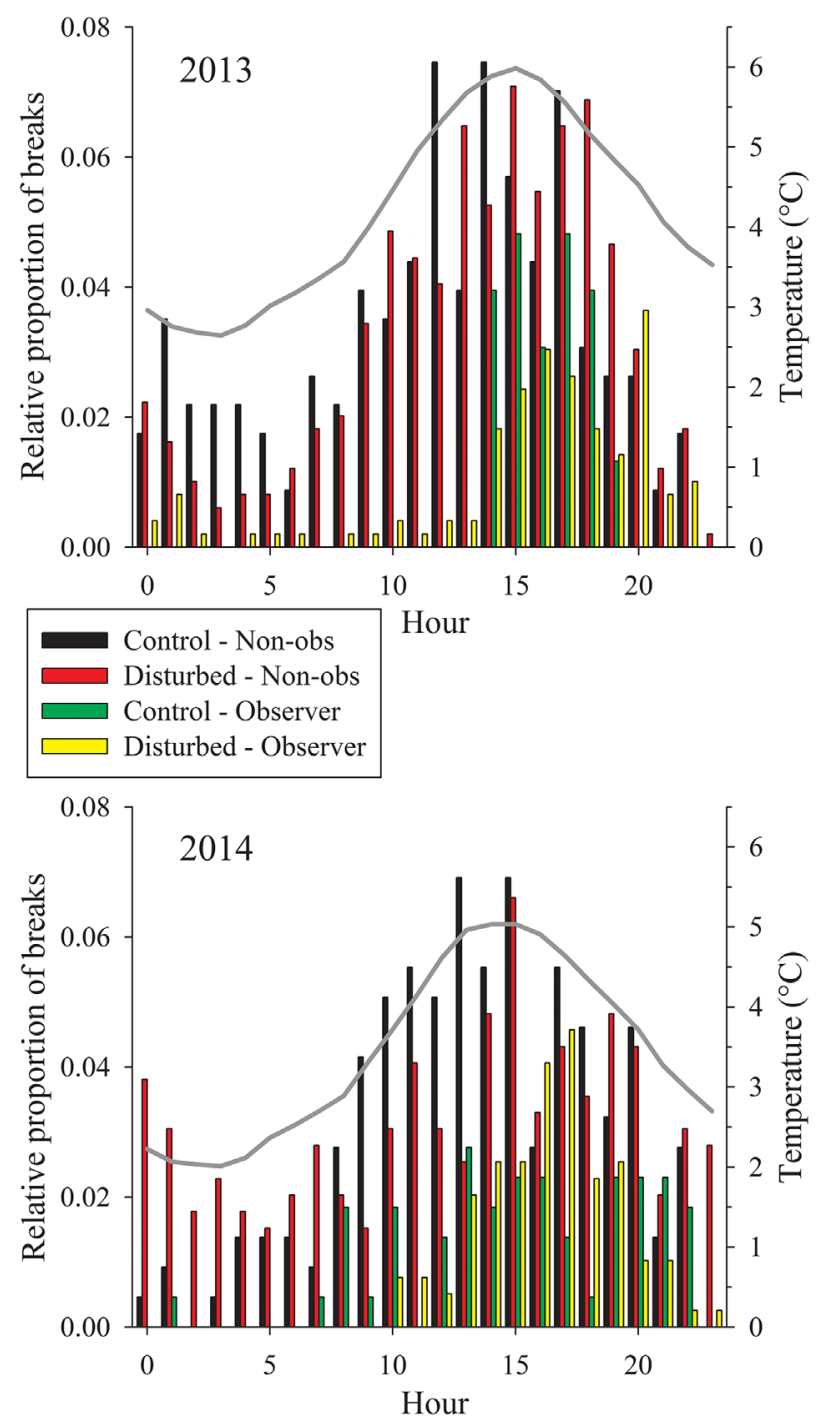

Figure 3. Relative frequency of incubation breaks taken by nesting whitefronted geese corresponding to hour of day on the Arctic Coastal Plain of Alaska, USA, 2013 (top) and 2014 (bottom). Observer-caused breaks are depicted by green (control site) and yellow (disturbed site) bars; nonobserver breaks (non-obs) are depicted by black (control site) and red (disturbed site) bars. Gray lines represent year-specific average ambient temperature during the nesting period (7 Jun-13 Jul).

observations categorized 36 nests as successful and 7 as failed. Of the 23 nests for which the source of nest failure was documented on camera, 10 failures were attributed to an observer nest visit, and these nests were either abandoned $(n=1)$, depredated by arctic foxes $(n=5)$, or depredated by avian predators $(n=4)$. Nest failures that occurred independent of observer nest visits were attributed to arctic foxes $(n=11)$, disturbance by an all-terrain vehicle (ATV) leading to depredation by an arctic fox $(n=1)$, and depredation by a brown bear $(n=1)$.

The top approximating model allowed HSP to vary by year, site, and day of incubation, by an observer effect that varied by site and year, and by distance from disturbance that varied by year (Table 1). Observer nest visits reduced HSP across sites and years, although the effect size varied by site-year. For nests in the disturbed site, HSP increased with distance 


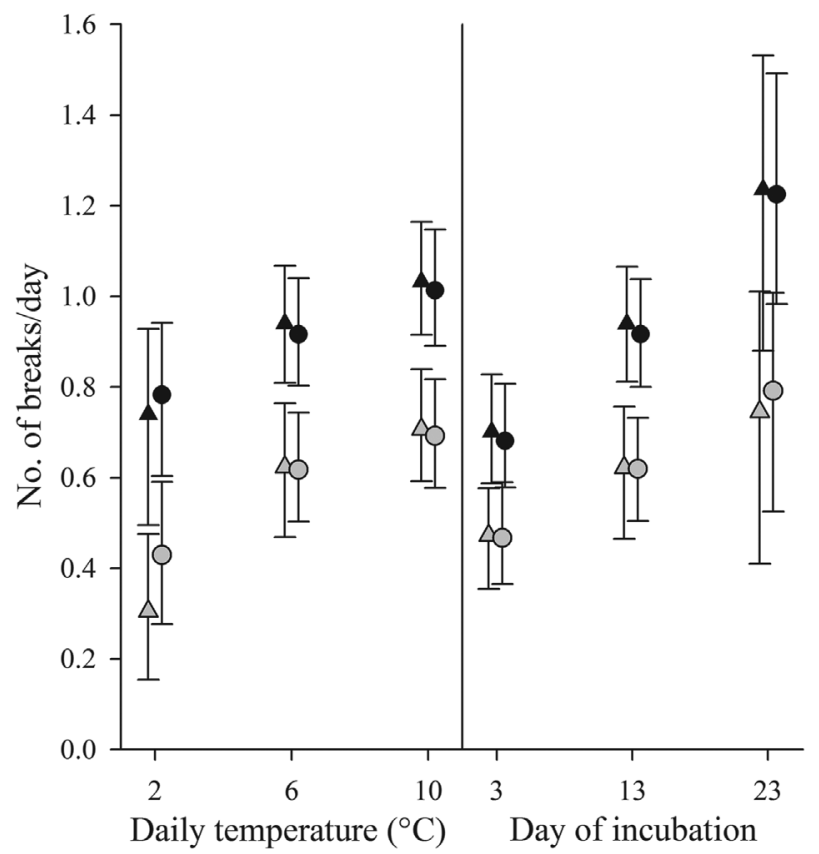

Figure 4. Predicted frequency of non-observer incubation breaks per day $( \pm 95 \% \mathrm{CI})$ relative to peak daily temperature (left) and day of incubation (right) for nesting white-fronted geese on the Arctic Coastal Plain of Alaska, USA, 2013 (triangles) and 2014 (circles). Black symbols depict nests in the disturbed site; gray symbols depict nests in the control site. We calculated predicted frequencies while holding additional sources of variation at mean values.

from industrial activity in 2013 ( $\hat{\beta}=0.004,85 \% \mathrm{CI}=0.001-$ $0.007)$, but the distance effect was equivocal in 2014 $(\hat{\beta}=-0.006,85 \% \mathrm{CI}=-0.014-0.002)$. Excluding observer effects, estimated nest success in the disturbed site during 2013 was $0.41 \pm 0.14$ (SE), $0.66 \pm 0.11$, and $0.79 \pm 0.11$ for a nest located $50 \mathrm{~m}, 250 \mathrm{~m}$, and $400 \mathrm{~m}$ from industrial activity, respectively, and was predicted to approximate nest success in the control site at a distance of $660 \mathrm{~m}$.

When excluding reductions to nest survival attributed to observer effects, nest success was considerably higher in the control $(\hat{S}=0.91 \pm 0.08)$ than disturbed site $(\hat{S}=0.62$ $\pm 0.10)$ in 2013 but was slightly higher in the disturbed site during $2014\left(\hat{S}_{\text {control }}=0.93 \pm 0.07, \hat{S}_{\text {disturbed }}=1.00\right)$, where the only 2 nest failures were attributed to observer visits. Using the model containing the same structure as the top approximating model but lacking an observer effect coefficient, estimated nest success representing all sources of failure differed only slightly for the control and disturbed sites in $2013\left(\hat{S}_{\text {control }}=0.60 \pm 0.13, \hat{S}_{\text {disturbed }}=0.55 \pm 0.10\right)$ and $2014\left(\hat{S}_{\text {control }}=0.86 \pm 0.09, \hat{S}_{\text {disturbed }}=0.92 \pm 0.07\right)$. The proportional reduction to nest success attributed to observer effects was highest for nests in the control site during 2013 (0.32), and similar for the remaining site-years (range $=0.07-0.08$; Table 2).

Daily survival of camera nests.-We analyzed encounter histories of the same 98 nests included in the HSP analysis but used nest visit data for 1,809 exposure days. Of all nests, 60 were considered successful, 32 were considered to have failed, and 6 were censored to the date that their camera was removed. For the 49 nests in which ultimate fate was documented on camera, all 23 failures were correctly identified on visits, whereas 2 of the 26 successful nests were incorrectly classified as failures in the field; one of these discrepancies occurred in each site during 2013. The top approximating model included a year effect (Table 3), where nest success in $2013(\hat{S}=0.46 \pm 0.07)$ was considerably lower than in $2014(\hat{S}=0.87 \pm 0.05)$. In contrast to the HSP analysis, we found only weak support for a positive relationship between DSP and distance from disturbance $\left(\Delta \mathrm{AIC}_{c}=0.71\right)$, and there was no support for variation in nest survival by site (Table 3 ).

When using the model structure most equivalent to the top approximating model from the HSP analysis (i.e., $S\{($ year $\times$ site $\times$ age $)+($ distance $\times$ year $)\})$ for comparison, estimates of nest success from the DSP analysis were similar in precision, and were generally lower than those from the HSP analysis, although the differences were most pronounced in 2013 (Table 2). Because we were unable to estimate an observer effect in the visit analysis, estimates were substantially lower (range $=0.07-0.49$ ) than those produced by the top approximating model in the HSP analysis (Table 2).

Camera effect.-To assess potential effects associated with the presence of cameras within the control site, we analyzed encounter histories of 40 nests with cameras $(2013=22$, $2014=18)$ and 97 nests without cameras $(2013=36$, $2014=61)$ for 2,321 exposure days. Excluding encounter histories for nests that were censored because of midincubation addition or removal of cameras $(n=8)$, apparent nest success in 2013 was $52.4 \%$ for camera nests and $62.5 \%$ for non-camera nests, and in 2014 was $83.3 \%$ for camera nests and $70.7 \%$ for non-camera nests. The top approximating model predicted that DSP varied by year and decreased with nest age; we found no support for an additive camera effect applied across years $\left(\Delta \mathrm{AIC}_{c}=2.00\right)$, and there was only weak support for a year-specific camera effect $\left(\Delta \mathrm{AIC}_{c}=1.35\right.$; Table 4$)$ in which the direction of the camera effect varied by year. Estimated nest success from the top approximating model was $0.57 \pm 0.07$ in 2013 and $0.71 \pm 0.05$ in 2014 .

\section{Predator Observations}

Photographs documented 187 predator occasions at nests. There were 55 apparent predator occasions that we attributed to arctic foxes although a predator was not apparent in photographs. In these cases, we observed nesting geese with wings spread in distinct nest-defense posture, a behavior that was initiated universally upon encroachment by arctic foxes (Fig. S1, available online in Supporting Information) but was not observed in response to any other predator or nonpredator species.

Arctic foxes were the most frequently documented predator $(n=150)$, accounting for $80 \%$ of all predator occasions, $61 \%$ of successful depredations, and $77 \%$ of predator-induced nest failures. Observations of avian predators at nests $(n=36)$ consisted of parasitic jaegers $(n=19)$, glaucous gulls $(n=13)$, common ravens $(n=3)$, 
Table 1. Models of hourly survival probability (HSP) of white-fronted goose nests monitored with digital time-lapse cameras on the Arctic Coastal Plain of Alaska, USA, 2013-2014. We conducted modeling in 2 stages; stage 1 models assessed support for variation in HSP relative to year, control versus disturbed sites (site), and day of incubation (age). We advanced the top approximating model from stage 1 to stage 2 to assess support for variation in HSP relative to observer effects (obs) and distance from industrial activities (dist). We applied the dist parameter only to nests in the disturbed site. Models are ranked by Akaike's Information Criterion corrected for sample size $\left(\mathrm{AIC}_{c}\right)$ and model weight $\left(w_{i}\right) . K=$ number of parameters. AIC $c$ of top approximating model $=328.66$

\begin{tabular}{|c|c|c|c|c|}
\hline HSP model & $K$ & $\Delta \mathrm{AIC}_{c}$ & $w_{i}$ & Deviance \\
\hline \multicolumn{5}{|l|}{ Stage 1} \\
\hline Yr $\times$ site $\times$ age & 8 & 0.00 & 0.43 & 361.27 \\
\hline $\mathrm{Yr}+$ site + age & 4 & 1.92 & 0.16 & 371.19 \\
\hline $\mathrm{Yr}$ & 2 & 1.97 & 0.16 & 375.25 \\
\hline$(\mathrm{yr} \times$ site $)+$ age & 5 & 3.62 & 0.07 & 370.89 \\
\hline $\mathrm{Yr}+$ site & 3 & 3.83 & 0.06 & 375.11 \\
\hline$(y r+$ site $)+($ age $\times y r)$ & 5 & 3.92 & 0.06 & 371.19 \\
\hline $\mathrm{Yr} \times$ site & 4 & 5.50 & 0.03 & 374.77 \\
\hline$(\mathrm{yr} \times$ site $)+($ age $\times$ yr $)$ & 6 & 5.61 & 0.03 & 370.88 \\
\hline Constant & 1 & 10.70 & 0.00 & 385.98 \\
\hline \multicolumn{5}{|l|}{ Stage 2} \\
\hline$(\mathrm{yr} \times$ site $\times$ age $)+($ obs $\times$ site $\times y r)+($ dist $\times y r)$ & 14 & 0.00 & 0.19 & 300.65 \\
\hline$(\mathrm{yr} \times$ site $\times$ age $)+($ obs $\times$ site $\times$ yr $)+$ dist & 13 & 0.39 & 0.16 & 303.04 \\
\hline$(\mathrm{yr} \times$ site $\times$ age $)+($ obs $\times$ site $)+($ dist $\times$ yr $)$ & 12 & 0.81 & 0.13 & 305.47 \\
\hline$(\mathrm{yr} \times$ site $\times$ age $)+($ obs $\times$ site $)+$ dist & 11 & 0.95 & 0.12 & 307.61 \\
\hline$(\mathrm{yr} \times$ site $\times$ age $)+($ obs $\times$ site $\times y r)$ & 12 & 1.07 & 0.11 & 305.73 \\
\hline$(\mathrm{yr} \times$ site $\times$ age $)+($ obs $\times$ site $)$ & 10 & 1.67 & 0.08 & 310.33 \\
\hline$(\mathrm{yr} \times$ site $\times$ age $)+$ obs $+($ dist $\times y r)$ & 11 & 2.77 & 0.05 & 309.42 \\
\hline$(\mathrm{yr} \times$ site $\times$ age $)+\mathrm{obs}+$ dist & 10 & 2.96 & 0.04 & 311.62 \\
\hline$(\mathrm{yr} \times$ site $\times$ age $)+($ obs $\times y r)+($ dist $\times y r)$ & 12 & 3.20 & 0.04 & 307.85 \\
\hline$(\mathrm{yr} \times$ site $\times$ age $)+($ obs $\times$ yr $)+$ dist & 11 & 3.49 & 0.03 & 310.15 \\
\hline$(\mathrm{yr} \times$ site $\times$ age $)+$ obs & 9 & 3.65 & 0.03 & 314.31 \\
\hline$(\mathrm{yr} \times$ site $\times$ age $)+(\mathrm{obs} \times \mathrm{yr})$ & 10 & 4.17 & 0.02 & 312.82 \\
\hline$(\mathrm{yr} \times$ site $\times$ age $)+(\text { dist } \times y r)^{\mathrm{a}}$ & 10 & 47.77 & 0.00 & 356.43 \\
\hline$(\mathrm{yr} \times$ site $\times$ age $)+$ dist & 9 & 47.81 & 0.00 & 358.46 \\
\hline Yr $\times$ site $\times$ age & 8 & 48.61 & 0.00 & 361.27 \\
\hline
\end{tabular}

${ }^{\text {a }}$ Model used to produce estimates of nest success that included all sources of nest failure to directly quantify reductions attributed to observer effects.

and snowy owls $(n=2)$. Predator species composition was similar among sites, although observations of common ravens occurred only in the disturbed site, and observations of snowy owls and a brown bear $(n=1)$ were limited to the control site. When the nesting female was present at the nest during a fox occasion $(n=143)$, aggressive nest defense usually deterred predation (Fig. S1), but foxes were successful 15 times (9.8\%; Fig. S2). In the absence of the female $(n=7)$, foxes were successful on all occasions. At least 7 nesting females were killed by a fox in 2013
(Figs. S3 and S4), but there were no such observations in 2014. Avian predators were unsuccessful on all of the 20 occasions during which the female was present but were successful on 13 of the 16 occasions when the female was absent (Fig. S5). Nine successful depredation events by avian predators occurred following an observer nest visit and the remaining 4 , each resulting in depredation of a single egg, occurred during a non-observer incubation break.

The number of fox occasions at nests varied considerably by year $(2013=118,2014=32)$, as did the number of

Table 2. Comparison of nest success estimates $(\hat{S}) \pm$ SE produced from analyses of hourly survival probability (HSP) and daily survival probability (DSP) of white-fronted goose nests monitored with digital time-lapse cameras on the Arctic Coastal Plain of Alaska, USA, 2013-2014. We derived estimates of HSP from photographs obtained at 1-minute intervals; we estimated DSP for the same nests, but encounter histories were based solely on information collected during observer nest visits at intervals of 5-7 days.

\begin{tabular}{lcccccr}
\hline Site-year & $\hat{\boldsymbol{S}}_{\text {HSP }}(\mathbf{N O F})^{\mathbf{a}}$ & $\hat{\boldsymbol{S}}_{\text {HSP }}(\mathbf{A S F})^{\mathbf{b}}$ & Observer effect $^{\mathbf{c}}$ & $\hat{\boldsymbol{S}}_{\text {DSP }}(\mathbf{C M})^{\mathbf{d}}$ & $\hat{\boldsymbol{S}}_{\text {HSP }}(\mathbf{N O F})-\hat{\boldsymbol{S}}_{\text {DSP }}(\mathbf{C M})$ & $\hat{\boldsymbol{S}}_{\text {HSP }}(\mathbf{A S F})-\hat{\boldsymbol{S}}_{\text {DSP }}(\mathbf{C M})$ \\
\hline Control-2013 & $0.91 \pm 0.08$ & $0.60 \pm 0.13$ & $0.32 \pm 0.15$ & $0.49 \pm 0.11$ & 0.42 & 0.11 \\
Disturbed-2013 & $0.62 \pm 0.10$ & $0.55 \pm 0.10$ & $0.07 \pm 0.14$ & $0.45 \pm 0.09$ & 0.18 & 0.10 \\
Control-2014 & $0.93 \pm 0.07$ & $0.86 \pm 0.09$ & $0.07 \pm 0.12$ & $0.83 \pm 0.09$ & 0.09 & 0.03 \\
Disturbed-2014 & 1.00 & $0.92 \pm 0.07$ & $0.08 \pm 0.07$ & $0.93 \pm 0.06$ & 0.07 & -0.01 \\
\hline
\end{tabular}

${ }^{a}$ Estimated nest success representing reductions from non-observer failures (NOF) only (i.e., excludes observer-caused failures) calculated using the topsupported HSP model without the observer effect coefficient.

${ }^{b}$ Estimated nest success including all sources of failure (ASF) calculated using the HSP model that did not contain an observer effect coefficient but was otherwise identical to the top-supported HSP model.

${ }^{c}$ Estimated magnitude of reductions to nest success attributed to observer nest visits calculated as $\hat{S}_{\mathrm{HSP}}(\mathrm{NOF})-\hat{S}_{\mathrm{HSP}}(\mathrm{AF})$.

${ }^{\mathrm{d}}$ Estimated nest success for camera-monitored nests from a post hoc DSP comparison model (CM) that was equivalent to the top-supported HSP model. 
Table 3. Models of daily survival probability (DSP) of white-fronted goose nests monitored on the Arctic Coastal Plain of Alaska, USA, $2013-2014$. Dataset includes only nests monitored with time-lapse cameras, but encounter histories were based solely on information collected during observer nest visits. We conducted modeling in 2 stages; stage 1 models assessed support for variation in DSP relative to year, control versus disturbed sites (site), and day of incubation (age). We advanced the top approximating model from stage 1 to stage 2 to assess support for variation in DSP relative to distance from industrial activities (dist). The dist parameter was applied only to nests in the disturbed site. Models are ranked by Akaike's Information Criterion corrected for sample size $\left(\mathrm{AIC}_{c}\right)$ and model weight $\left(w_{i}\right) . K=$ number of parameters. $\mathrm{AIC}_{c}$ of top approximating model $=213.86$.

\begin{tabular}{|c|c|c|c|c|}
\hline DSP model & $K$ & $\Delta \mathrm{AIC}_{c}$ & $w_{i}$ & Deviance \\
\hline \multicolumn{5}{|l|}{ Stage 1} \\
\hline $\mathrm{Yr}$ & 2 & 0.00 & 0.50 & 197.52 \\
\hline $\mathrm{Yr}+$ site & 3 & 2.01 & 0.18 & 197.52 \\
\hline $\mathrm{Yr} \times$ site & 4 & 3.37 & 0.09 & 196.87 \\
\hline $\mathrm{Yr}+$ site + age & 4 & 3.44 & 0.09 & 196.94 \\
\hline$(\mathrm{yr} \times$ site $)+$ age & 5 & 4.80 & 0.05 & 196.29 \\
\hline$(\mathrm{yr}+$ site $)+($ age $\times$ yr $)$ & 5 & 5.25 & 0.04 & 196.74 \\
\hline Yr $\times$ site $\times$ age & 8 & 5.47 & 0.03 & 190.91 \\
\hline$(\mathrm{yr} \times$ site $)+($ age $\times$ yr $)$ & 6 & 6.61 & 0.02 & 196.09 \\
\hline Constant & 1 & 16.18 & 0.00 & 215.70 \\
\hline \multicolumn{5}{|l|}{ Stage 2} \\
\hline $\mathrm{Yr}$ & 2 & 0.00 & 0.46 & 197.52 \\
\hline $\mathrm{Yr}+$ dist & 3 & 0.71 & 0.32 & 196.22 \\
\hline $\mathrm{Yr}+($ dist $\times \mathrm{yr})$ & 4 & 2.11 & 0.16 & 195.61 \\
\hline$(\mathrm{yr} \times$ site $\times$ age $)+(\text { dist } \times y r)^{\mathrm{a}}$ & 10 & 4.21 & 0.06 & 185.61 \\
\hline
\end{tabular}

${ }^{a}$ Model constructed post hoc and used to produce nest success estimates for direct comparison to the camera-hourly survival probability analysis.

fox depredation events $(2013=20,2014=2)$. When scaled relative to the number of interpretable photographs obtained per year, this equates to 1.45 fox occasions $/ 10,000$ photos and 0.25 depredation events $/ 10,000$ photos in 2013 compared to 0.39 fox occasions $/ 10,000$ photos and 0.02 depredation events/10,000 photos in 2014. The relative proportion of fox occasions and depredation events in the disturbed site were similar to or higher than those in the control site, whereas the proportion of avian predator occasions and depredation events was higher in the control than disturbed site during both years (Table 5). Fox occasions occurred throughout the day but were relatively more common during low-light periods (Fig. 5). In contrast, avian predator occasions occurred more frequently during mid-day hours (Fig. 5).

\section{DISCUSSION}

We found evidence for a minor effect of industrial activity on the incubation behavior of white-fronted geese nesting in the NPR-A. Females maintained high levels of incubation constancy in industrial and control areas, and were effective at deterring predators when present at their nests. Nest cameras allowed us to demonstrate that females took much longer incubation breaks after being flushed from their nests by researchers, and that predators exploited these absences by depredating eggs. Arctic foxes were responsible for most nest failures but their behavior varied among years, likely in response to lemming (Lemmus trimucronatus, Dicrostonyx groenlandicus) abundance. Industrial development may negatively affect productivity of nesting geese to the extent that infrastructure tends to attract predators to the area or that industrial activities lead to direct encroachment at nests; effects of indirect vehicular and aircraft disturbance appear to be trivial.

White-fronted geese showed high levels of nest attendance, initiating short incubation breaks less than once a day. High rates of incubation constancy are particularly important to the productivity of tundra-nesting geese where short vegetation height provides little visual concealment to unattended nests, and eggs are more susceptible to predation in the absence of incubating adults (Samelius and Alisauskas 2001, Bêty et al. 2002). It appears advantageous for females to maximize incubation constancy to the greatest extent allowed by endogenous reserves or supplemental feeding during nesting (Prop et al. 1984, Reed et al. 1995). Our estimates of incubation constancy are within the range of those reported for other populations of white-fronted geese, and our estimate of 8.7 minutes for average duration of non-observer incubation breaks is similar to an estimate from Arctic Alaska ( $8 \mathrm{~min}$ ) but shorter than reported for white-fronted geese nesting in Greenland (24 min), Russia (17 min), and Alaska's Yukon-Kuskokwim Delta (24 min; Afton and Paulus 1992).

In both years of our study, non-observer incubation breaks occurred 1.5 times more frequently in the disturbed than control site, and both the length and frequency of these breaks decreased with distance from disturbance. Taken together, these results provide evidence for disturbancecaused effects on nest attendance. However, the difference in break frequency between disturbed and control sites averaged 0.3 breaks/day, which represents the maximum increase in break frequency attributable to industry-caused disturbance. Non-observer breaks averaged approximately 9 minutes, and therefore the realized effect of industrial activities on overall incubation constancy was an average increase in nest absence of $<3$ minutes/day. Given that industrial activities occurred within the disturbed site on a daily basis, it is apparent that the majority of potential disturbance events did not induce incubation breaks. Even repeated low-level helicopter flight directly over nests (Fig. 1E), and landings and takeoffs of large aircraft (e.g., Douglas DC-6; Douglas Aircraft Company, Santa Monica, CA, USA) close to nests 
Table 4. Models of daily survival probability (DSP) of white-fronted goose nests in the control site on the Arctic Coastal Plain of Alaska, USA, 2013-2014. Dataset includes nests monitored with and without time-lapse cameras, but encounter histories were based solely on information collected during observer nest visits. We conducted modeling in 2 stages; stage 1 models assessed support for variation in DSP relative to year and day of incubation (age). We advanced the top approximating model from stage 1 to stage 2 to assess support for variation in DSP relative to the presence of time-lapse cameras (camera). Models are ranked by Akaike's Information Criterion corrected for sample size $\left(\mathrm{AIC}_{c}\right)$ and model weight $\left(w_{i}\right)$. $K=$ number of parameters. AIC $_{c}$ of top approximating model $=259.41$.

\begin{tabular}{lcccc}
\hline \multicolumn{1}{c}{ DSP model } & $\boldsymbol{K}$ & $\boldsymbol{\Delta} \mathbf{A I C}_{\boldsymbol{c}}$ & $\boldsymbol{w}_{\boldsymbol{i}}$ & Deviance \\
\hline Stage 1 & & & & \\
Yr + age & 3 & 0.00 & 0.67 & 253.39 \\
Yr $\times$ age & 4 & 1.93 & 0.25 & 253.32 \\
Yr & 2 & 5.56 & 0.04 & 260.96 \\
$\quad$ Constant & 1 & 5.96 & 0.03 & 263.36 \\
Stage 2 & & & & \\
Yr + age & 3 & 0.00 & 0.53 & 253.39 \\
$\quad$ (yr $\times$ camera) + age & 5 & 1.35 & 0.27 & 250.73 \\
Yr + age + camera & 4 & 2.00 & 0.20 & 253.38 \\
\hline
\end{tabular}

(Fig. S6), were rarely associated with nest absence; the most common response to vehicular traffic was for females to extend their necks and lie flat in a hiding posture (Figs. S6 and S7). The high degree of predation pressure, combined with the increased risk of depredation to unattended nests, was likely the primary factor influencing the tolerance of incubating geese to industrial activities.

We hypothesized that if anthropogenic activities decreased incubation constancy, nests would suffer from increased rates of egg depredation. Consistent with predictions of industrycaused effects, nest survival was considerably lower in the disturbed than control site during 2013, and the probability of a nest hatching increased strongly with increasing distance from industrial activities. However, if observer-caused failures are excluded, nest success was $100 \%$ in the disturbed site in 2014. Thus, although females in the disturbed site were absent from their nests more frequently in 2014, the effect was not realized through site-specific variation in nest survival. Whereas the number of avian predator occasions at nests was similar among years in the disturbed site, cameras documented 10 times as many fox depredations and nearly 4 times the number of fox observations in 2013 than 2014. Bêty et al. (2002) demonstrated reduced arctic fox predation pressure on Arctic-nesting greater snow geese (Anser caerulescens atlanticus) during years with high abundance of lemmings, their preferred prey, and increased rates of attack on geese during low lemming years. Our general observations of lemming abundance support the pattern reported by Bêty et al. (2002), and the principle factor explaining the annual difference in fox depredations was likely variation in fox behavior influenced by changes in lemming abundance. Hence, although our measure of industry-caused disturbance on incubation constancy was similar across years, the lack of a measurable reduction to nest survival in 2014 demonstrates that the realized magnitude of industry-mediated effects on avian productivity is subject to annual variation in behavior or abundance of predators, and in this case, arctic foxes.

Observer nest visits were responsible for reductions of 7$35 \%$ in estimated nest survival probability over the 24 -day incubation period, which was likely a function of the 5-fold increase in break length following observer visits as compared to those caused by other sources. These results demonstrate potential biases and deleterious consequences associated with visit-based studies of avian reproductive success in the Arctic, and are consistent with results from recent studies involving king eiders (Somateria spectabilis; Bentzen et al. 2008), common eiders (Somateria mollissima; Stien and Ims 2015), and loons (Gavia spp.; Uher-Koch et al. 2015). But perhaps more importantly, these results demonstrate a differential response by nesting geese to varying types of disturbance. Whereas observer visits were associated with direct human encroachment at nests, sources of industrial disturbance in our study were characterized primarily by vehicular, aircraft, and foot travel on existing gravel surfaces that followed similar routes and usually did not directly approach nest sites. Furthermore, conclusive evidence for nest failure induced by industrial disturbance based on camera data is minimal. Within the disturbed site, only a single nest failure was attributed to vehicular disturbance as compared to 4 failures that followed observer nest visits. Similarly, a study assessing the effects of regular industrial activity on common eider reproductive success in Arctic Alaska (Johnson et al. 1987) attributed 11 of 12 disturbance-induced nest failures to observer activities. It is possible that industrial activity indirectly contributed to some proportion of observer-caused nest failures in our study, but although we attributed the increased frequency of non-observer incubation breaks within the disturbed site to industrial disturbance, it appears

Table 5. Proportion of documented predator occasions and depredation events (per 10,000 interpretable photographs) obtained from digital time-lapse cameras at white-fronted goose nests in control and disturbed sites on the Arctic Coastal Plain of Alaska, USA, 2013-2014. Proportions are scaled relative to the site- and year-specific number of interpretable photographs obtained. Depredations represent occasions in which a predator successfully destroyed at least one egg.

\begin{tabular}{|c|c|c|c|c|c|c|}
\hline \multirow[b]{2}{*}{ Site-year } & \multicolumn{2}{|c|}{ Avian predators } & \multicolumn{2}{|c|}{ Arctic fox } & \multicolumn{2}{|c|}{ All predators ${ }^{a}$} \\
\hline & Occasions & Depredations & Occasions & Depredations & Occasions & Depredations \\
\hline Control-2013 & 0.27 & 0.11 & 1.29 & 0.23 & 1.56 & 0.34 \\
\hline Disturbed-2013 & 0.18 & 0.05 & 1.52 & 0.25 & 1.70 & 0.31 \\
\hline Control-2014 & 0.30 & 0.12 & 0.39 & 0.00 & 0.72 & 0.15 \\
\hline Disturbed-2014 & 0.18 & 0.06 & 0.39 & 0.04 & 0.57 & 0.10 \\
\hline
\end{tabular}

${ }^{a}$ Includes all avian predator and fox occasions and the single depredation of a nest by a brown bear in the control site during 2014. 

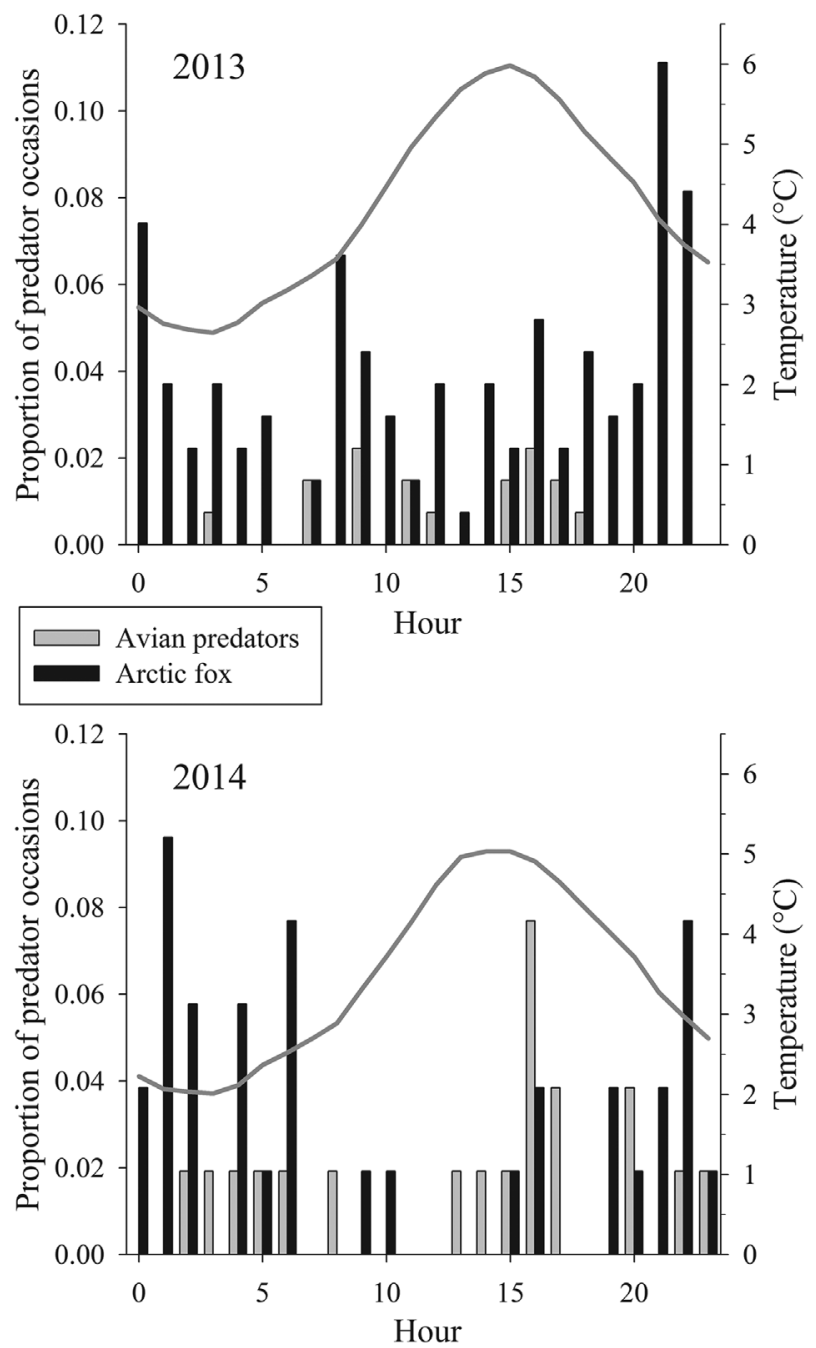

Figure 5. Relative proportion of predator occasions recorded by digital time-lapse cameras at white-fronted goose nests on the Arctic Coastal Plain of Alaska, USA, 2013 (top) and 2014 (bottom). Occasions are delineated by predator type (gray $=$ avian, black $=$ arctic fox $)$ and hour of day. Solid lines depict year-specific average ambient temperature during the nesting period (7 Jun-13 Jul).

as though these breaks were generally of short enough duration to minimize complete clutch loss.

Arctic foxes were the most important predator in our study, accounting for a large majority of depredations and predator occasions at nest sites. Similarly, a camera study assessing predation of shorebird and passerine nests at a nearby study site attributed 5 of 6 nest failures to arctic foxes (Liebezeit and Zack 2008). Because only $10 \%$ of fox visits occurring in the presence of a nesting female resulted in depredations, our data demonstrate that nesting white-fronted geese are frequently, but not always, capable of defending their nests from arctic foxes. Likewise, the successful nest defense rate by incubating greater snow geese, a similarly sized Arcticnesting goose, against arctic foxes was $92 \%$ (Bêty et al. 2002). A study using cameras to monitor nesting white-fronted geese in Arctic Alaska showed perfect rates of successful nest defense against arctic foxes, although sample sizes were considerably smaller (Johnson et al. 2003). Whereas avian predators were frequently documented in photographs at nest sites in our study, they were only successful at depredating eggs in the absence of the incubating female, and the majority of these coincided with observer-caused incubation breaks. Hence, outside of human influence, the impact of avian predators on white-fronted goose productivity was negligible. We suggest that nesting females successfully mitigated the threat of avian depredation through high rates of nest attendance and by minimizing the length of incubation breaks.

Higher abundance of arctic foxes within oil fields on the Arctic Coastal Plain, as compared to nearby undeveloped areas, has been attributed to the availability of supplementary food and human-made structures for denning (NRC 2003). During both years of our study, we observed arctic fox adults and pups inhabiting abandoned buildings at the radar station (Fig. S8). We cannot rule out a potential relationship between industrial activity and fox behavior, but we suspect that the higher frequency of fox visits and depredation events at nests within the disturbed site was associated with their proximity to human-made infrastructure. Whereas the majority of industrial activities could not be seen or heard from the control site, the distance from the radar station to nests in the control site was within the extent of the arctic fox summer home-range size (Eberhardt et al. 1982), and many nests in the control site were $<5 \mathrm{~km}$ from infrastructure, which is the distance within which reductions to passerine nest survival were documented by Liebezeit et al. (2009). However, the control site was separated from the disturbed site by a branch of the Smith River. Arctic foxes are capable of swimming considerable distances (Strub 1992), although numerous observations suggest that they are reluctant to swim on a regular basis (Mickelson 1975, Thompson and Raveling 1987, Robertson 1995) and we doubt that an infrastructure effect on predators extended into the control site.

The presence of infrastructure and industrial activity did not appear to deter nesting white-fronted geese. Many nests were located immediately adjacent to gravel roads and within patches of tundra among buildings, radar antennas, and pipelines (Figs. S9 and S10). Furthermore, during 2014 when industrial activities began prior to nest initiation, there were numerous nests established within meters of travel routes and centers of activity. A multi-year study conducted before and during construction of a runway at an oil production facility on the Colville River Delta $(100 \mathrm{~km}$ from our study site) reported reduced white-fronted goose nest densities within $700 \mathrm{~m}$ during the years of construction (Johnson et al. 2003). We found no evidence that a similar effect occurred on our study area because there were more nests located within $100 \mathrm{~m}$ of disturbance in $2014(n=18)$ than $2013(n=13)$.

Incubation breaks occurring independent of observer nest visits were most common during the warmest period of the day, and the probability of a non-observer break was higher on days with warmer temperatures. Such patterns are frequently observed among nesting waterfowl, and may be attributed to minimizing the cooling of eggs or reducing exposure of unattended nests to predators (Thompson and 
Raveling 1987, Flint and Grand 1999, Tombre et al. 2012). Photographs of foxes at nests were relatively more common during low-light hours associated with the coolest portions of the day and highest rates of nest attentiveness, whereas peaks in the frequency of avian predators corresponded with the warmest period of the day and peak timing of incubation breaks. Given the relative threat of fox predation compared to the negligible impact of avian predators on nest survival, nesting white-fronted geese appeared to successfully balance timing of incubation breaks with peaks in ambient temperatures, which allowed them to be present at nests during periods of heightened fox activity.

Analysis of hourly nest survival using camera data yielded improved inference by allowing us to detect considerably greater detail in patterns of variation as compared to the DSP analysis informed by visit data for the same nests. The camera data also yielded improvements in accuracy, which we largely attribute to the lack of uncertainty in identifying nest fate. However, precision among method-specific estimates differed little at the level of nest success. Calculating variance associated with cumulative survival probabilities using the delta method required the product of 576 HSP estimates over the 24-day incubation period, as compared to the product of only 24 DSP estimates (Seber 1982). As such, relative gains in precision were minimal when extrapolating over the entire incubation period. Camera monitoring also provided supplemental information generally not obtainable through traditional visit-based data collection, including the ability to identify predators to species and document behavior of both predators and geese. Consistent with results from previous studies in the Arctic (Liebezeit and Zack 2008, McKinnon and Bêty 2009, Stien and Ims 2015), we found no effect of cameras on nest survival. Thus, remote cameras provide an opportunity to strengthen inference and reduce observer impacts when monitoring avian productivity, especially in cases where study objectives can be met without data obtained by recurring human visits to nests.

\section{MANAGEMENT IMPLICATIONS}

The risk of depredation to eggs of nesting geese in the Arctic increases substantially when nests are unattended. Thus, the primary threats of human activity to productivity are actions that cause incubating females to be absent from their nests. Whereas direct encroachment by investigators at nest sites caused prolonged incubation recesses and increased the probability of egg depredation, indirect vehicular and aircraft traffic had relatively minor impacts on nest attendance and survival, and the effects of industrial activity on incubation constancy were estimated to be zero at a distance of $710 \mathrm{~m}$. If a goal is to minimize impacts of industrial activities on avian productivity in the Arctic, our findings support avoidance of pedestrian and vehicular travel on the tundra to the extent possible during the nesting period, and restriction of travel to established routes. Furthermore, we suggest that studies of avian productivity in the Arctic directly account for potential biases associated with investigator-caused disturbance and limit nest visits to the maximum extent that study objectives allow.

\section{ACKNOWLEDGMENTS}

Use of trade, product, or company names is solely for descriptive purposes and does not imply endorsement by the U.S. Government. Data presented in this paper are publicly available via the United States Geological Survey (USGS) Alaska Science Center (DOI:10.5066/ F7NV9GP9). Nest camera photographs are archived at the USGS Alaska Science Center. We thank T. J. Spivey, M. K. Johnson, T. G. Peterson, C. L. Twellmann, L. R. Burlingame, and C. M. Hansen for their hard work monitoring nests, managing cameras, and evaluating photographs. J. A. Schmutz, J. M. Pearce, and C. B. Johnson provided helpful reviews of the manuscript. We thank M. E. Whalen for assistance with figures and D. H. Walworth for data management support. This work is part of the U.S. Geological Survey's Changing Arctic Ecosystem Initiative and is supported by funding from the Wildlife Program of the USGS Ecosystem Mission Area. Funding and logistical support were also provided by the Bureau of Land Management (D. A. Nigro, Arctic Office).

\section{LITERATURE CITED}

Afton, A. D., and S. L. Paulus. 1992. Incubation and brood care. Pages 62-108 in B. D. J. Batt, A. D. Afton, M. G. Anderson, C. D. Ankney, D. H. Johnson, J. A. Kadlec, and G. L. Krapu, editors. Ecology and management of breeding waterfowl. University of Minnesota Press, Minneapolis, USA.

Anthony, R. M., J. B. Grand, T. F. Fondell, and B. F. Manly. 2004. A quantitative approach to identifying predators from nest remains. Journal of Field Ornithology 75:40-48.

Anthony, R. M., J. B. Grand, T. F. Fondell, and D. A. Miller. 2006. Techniques for identifying predators of goose nests. Wildlife Biology 12:249-256.

Arnold, T. W. 2010. Uninformative parameters and model selection using Akaike's Information Criterion. Journal of Wildlife Management 74: 1175-1178.

Bentzen, R. L., A. N. Powell, and R. S. Suydam. 2008. Factors influencing nesting success of king eiders on northern Alaska's coastal plain. Journal of Wildlife Management 72:1781-1789.

Bêty, J., and G. Gauthier. 2001. Effects of nest visits on predator activity and predation rate in a greater snow goose colony. Journal of Field Ornithology 72:573-586.

Bêty, J., G. Gauthier, E. Korpimäki, and J. F. Giroux. 2002. Shared predators and indirect trophic interactions: lemming cycles and arcticnesting geese. Journal of Animal Ecology 71:88-98.

Bolduc, F., and M. Guillemette. 2003. Human disturbance and nesting success of common eiders: interaction between visitors and gulls. Biological Conservation 110:77-83.

Bureau of Land Management [BLM]. 2015. Supplemental Environmental Impact Statement for the Alpine Satellite Development Plan for the Proposed Greater Mooses Tooth One Development Project. Record of Decision. U.S. Department of the Interior, Bureau of Land Management, Anchorage, Alaska, USA.

Burnham, K. P., and D. R. Anderson. 2002. Model selection and multimodel inference: a practical information-theoretic approach. Second edition. Springer-Verlag, New York, New York, USA.

Carney, K. M., and W. J. Sydeman. 1999. A review of human disturbance effects on nesting colonial waterbirds. Waterbirds 22:68-79.

Coates, P. S., J. W. Connelly, and D. J. Delehanty. 2008. Predators of greater sage grouse nests identified by video monitoring. Journal of Field Ornithology 79:421-428.

Dinsmore, S. J., G. C. White, and F. L. Knopf. 2002. Advanced techniques for modeling avian nest survival. Ecology 83:3476-3488.

Eberhardt, L. E., W. C. Hanson, J. L. Bengtson, R. A. Garrott, and E. E. Hanson. 1982. Arctic fox home range characteristics in an oildevelopment area. Journal of Wildlife Management 46:183-190. 
Ely, C. R., and A. X. Dzubin. 1994. Greater white-fronted goose (Anser albifrons). Account 131 in A. Poole and F. Gill, editors. The birds of North America. The Academy of Natural Sciences, Philadelphia, Pennsylvania, and The American Ornithologists' Union, Washington, D.C., USA.

Flint, P. L., and J. B. Grand. 1999. Incubation behavior of spectacled eiders on the Yukon-Kuskokwim Delta, Alaska. Condor 101:413-416.

Flint, P. L., and J. S. Sedinger. 1992. Reproductive implications of egg-size variation in the black brant. Auk 109:896-903.

Gallant, A. L., E. F. Binnian, J. M. Omernik, and M. B. Shasby. 1995. Ecoregions of Alaska. U. S. Geological Survey Professional Paper 1567. United States Government Printing Office, Washington, D. C., USA.

Gladwin, D. N., D. A. Asherin, and K. M. Manci. 1987. Effects of aircraft noise and sonic booms on fish and wildlife: results of a survey of U.S. Fish and Wildlife Service Endangered Species and Ecological Services Field Offices, Refuges, Hatcheries, and Research Centers. NERC-88/30. U.S. Fish and Wildlife Service, National Ecology Research Center, Fort Collins, Colorado, USA.

Hockin, D., M. Ounsted, M. Gorman, D. Hill, V. Keller, and M. Barker. 1992. Examination of the effects of disturbance on birds with reference to its importance in ecological assessments. Journal of Environmental Management 36:253-286.

Hoover, A. K., F. C. Rohwer, and K. D. Richkus. 2004. Evaluation of nest temperatures to assess female nest attendance and use of video cameras to monitor incubating waterfowl. Wildlife Society Bulletin 32:581-587.

Johnson, C. B., R. M. Burgess, B. E. Lawhead, J. A. Neville, J. P. Parrett, A. K. Prichard, J. R. Rose, A. A. Stickney, and A. M. Wildman. 2003. Alpine avian monitoring program, 2001. Unpublished report to ConocoPhillips Alaska, Inc., Anchorage, USA, and Anadarko Petroleum Corporation, Anchorage, Alaska, USA, prepared by ABR, Inc., Fairbanks, Alaska, USA.

Johnson, S. R., D. R. Herter, and M. S. Bradstreet. 1987. Habitat use and reproductive success of Pacific eiders Somateria mollissima v-nigra during a period of industrial activity. Biological Conservation 41:77-89.

Jónsson, J. E., A. D. Afton, and R. T. Alisauskas. 2007. Does body size influence nest attendance? A comparison of Ross's geese (Chen rossii) and the larger, sympatric lesser snow geese (C. caerulescens caerulescens). Journal of Ornithology 148:549-555.

Klett, A. T., H. F. Duebbert, C. A. Faanes, and K. F. Higgins. 1986. Techniques for studying nest success of ducks in upland habitats in the prairie pothole region. U.S. Fish and Wildlife Service Resource Publication 158, Washington, D.C., USA.

Larivière, S. 1999. Reasons why predators cannot be inferred from nest remains. Condor 101:718-721.

Liebezeit, J., S. Kendall, S. Brown, C. Johnson, P. Martin, T. McDonald, D. Payer, C. Rea, B. Streever, and A. Wildman. 2009. Influence of human development and predators on nest survival of tundra birds, Arctic Coastal Plain, Alaska. Ecological Applications 19:1628-1644.

Liebezeit, J. R., and S. Zack. 2008. Point counts underestimate the importance of arctic foxes as avian nest predators: evidence from remote video cameras in Arctic Alaskan oil fields. Arctic 61:153-161.

Mayfield, H. 1961. Nesting success calculated from exposure. Wilson Bulletin 73:255-261.

McKinnon, L., and J. Bêty. 2009. Effect of camera monitoring on survival rates of high-Arctic shorebird nests. Journal of Field Ornithology 80:280-288.

Mickelson, P. G. 1975. Breeding biology of cackling geese and associated species on the Yukon-Kuskokwim Delta, Alaska. Wildlife Monographs 45:3-35.

National Research Council [NRC]. 2003. Cumulative environmental effects of oil and gas activities on Alaska's North Slope. National Academies Press, Washington, D.C., USA.

Pietz, P. J., and D. A. Granfors. 2000. Identifying predators and fates of grassland passerine nests using miniature video cameras. Journal of Wildlife Management 64:71-87.

Prop, J., M. R. van Eerden, and R. H. Drent. 1984. Reproductive success of the barnacle goose Branta leucopsis in relation to food exploitation on the breeding grounds, western Spitsbergen. Norsk Polarinstitutt Skrifter 181:87-116.
Reed, A., R. J. Hughes, and G. Gauthier. 1995. Incubation behavior and body mass of female greater snow geese. Condor 97:993-1001.

Richardson, T., T. Gardali, and S. H. Jenkins. 2009. Review and metaanalysis of camera effects on avian nest success. Journal of Wildlife Management 73:287-293.

Robertson, G. J. 1995. Factors affecting nest site selection and nesting success in the common eider Somateria mollissima. Ibis 137:109-115.

Rotella, J. J., S. J. Dinsmore, and T. L. Shaffer. 2004. Modeling nest-survival data: a comparison of recently developed methods that can be implemented in MARK and SAS. Animal Biodiversity and Conservation 27:187-205.

Rotella, J. J., M. L. Taper, and A. J. Hansen. 2000. Correcting nestingsuccess estimates for observer effects: maximum-likelihood estimates of daily survival rates with reduced bias. Auk 117:92-109.

Samelius, G., and R. T. Alisauskas. 2001. Deterring arctic fox predation: the role of parental nest attendance by lesser snow geese. Canadian Journal of Zoology 79:861-866.

Sargeant, A. B., M. A. Sovada, and R. J. Greenwood. 1998. Interpreting evidence of depredation of duck nests in the prairie pothole region. U.S. Geological Survey, Northern Prairie Wildlife Research Center, Jamestown, North Dakota, USA, and Ducks Unlimited, Inc., Memphis, Tennessee, USA.

Seber, G. A. F. 1982. The estimation of animal abundance and related parameters. Second edition. Macmillan, New York, New York, USA.

Stehn, R., W. Larned, and R. Platte. 2013. Analysis of aerial survey indices monitoring waterbird populations of the Arctic Coastal Plain, Alaska, 1986-2012. U.S. Fish and Wildlife Service, Migratory Bird Management, Anchorage, Alaska, USA.

Stien, J., and R. A. Ims. 2015. Absence from the nest due to human disturbance induces higher nest predation risk than natural recesses in common eiders Somateria mollissima. Ibis 158:249-260.

Strub, H. 1992. Swim by an arctic fox, Alopex lagopus, in Alexandra Fiord, Ellesmere Island, Northwest Territories. Canadian Field-Naturalist 106:513-514.

Tape, K. D., P. L. Flint, B. W. Meixell, and B. V. Gaglioti. 2013. Inundation, sedimentation, and subsidence creates goose habitat along the Arctic coast of Alaska. Environmental Research Letters 8:045031.

Thompson, S. C., and D. G. Raveling. 1987. Incubation behavior of emperor geese compared with other geese: interactions of predation, body size, and energetics. Auk 104:707-716.

Tombre, I. M., K. E. Erikstad, and V. Bunes. 2012. State-dependent incubation behaviour in the high arctic barnacle geese. Polar Biology 35:985-992.

Uher-Koch, B. D., J. A. Schmutz, and K. G. Wright. 2015. Nest visits and capture events affect breeding success of yellow-billed and Pacific loons. Condor 117:121-129.

Urban, F. E., and G. D. Clow. 2016. DOI/GTN-P Climate and active-layer data acquired in the National Petroleum Reserve-Alaska and the Arctic National Wildlife Refuge, 1998-2014. U.S. Geological Survey Data Series 977, Denver, Colorado, USA.

Weller, M. W. 1956. A simple field candler for waterfowl eggs. Journal of Wildlife Management 20:111-113.

Weller, M. W., and D. V. Derksen. 1972. Use of time-lapse photography to study nesting activities of birds. Auk 89:196-200.

Williams, G. E., P. B. Wood, and F. Thompson III. 2002. Are traditional methods of determining nest predators and nest fates reliable? An experiment with wood thrushes (Hylocichla mustelina) using miniature video cameras. Auk 119:1126-1132.

Wilson, H. M., P. L. Flint, A. N. Powell, J. B. Grand, and C. L. Moran. 2012. Population ecology of breeding Pacific common eiders on the Yukon-Kuskokwim Delta, Alaska. Wildlife Monographs 182:1-28.

Associate Editor: Bev Gingras.

\section{SUPPORTING INFORMATION}

Additional supporting information may be found in the online version of this article at the publisher's website. 